\title{
动力分析的电化学自动测定 天然水中痕量碘
}

王庆璋陈德昌

(山东海洋学院海洋化学系)

动力分析中的催化反应实际上多属简单的氧化一还原反应, 应用日益发展起来的电极测量 技术, 能使预知的反应速度转化为电参数一时间关系, 从而可以扩大参数测量范围, 简化数据 处理,适应微样分析, 便于自动记录。

本工作采用玻璃石墨电极和电位测量记录装置, 对海水、间隙水和人工降雨中的微量碘进 行了分析,闰时与光度法 ${ }^{[1]}$ 做了对照研究.

\section{理 论 根 据}

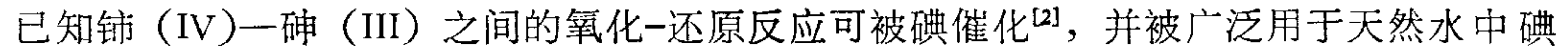
的测定 ${ }^{[3-6]}$. 当砷 (III) 浓度固定后, 其反应速度方程为

$$
-\frac{d[\mathrm{Ce}(\mathrm{IV})]}{d t}=\left\{k_{0}+k_{\mathrm{I}}[\mathrm{I}]+\sum k_{\mathrm{i}}[\mathrm{i}]\right\}[\mathrm{Ce}(\mathrm{IV})] \text {, }
$$

式中 $k_{0}$ 是反应速度常数, $k_{1}$ 是倎的催化反应速度常数， $k_{\mathrm{i}}$ 是对该反应有影响的物盾 $\mathrm{i}$ 所具有 的干扰系数. 因海水组成相对稳定, 综合干扰项 $\sum k_{\mathrm{i}}[\mathrm{i}]$ 可简化为盐度单值函数 $k_{S} S$, 故 (1) 式为

$$
-\frac{d[\mathrm{Ce}(\mathrm{IV})]}{d t}=\left\{k_{0}+k_{\mathrm{I}}[\mathrm{I}]+k_{s} S\right\}[\mathrm{Ce}(\mathrm{IV})],
$$

$S$ 是海水盐度, $k s$ 是与盐度和样品稀释倍数有关的综合干扰系数.

实验表明该体系中指示电极的电位基本上受反应: $\mathrm{CeSO}_{4}{ }^{2+}+\mathrm{e}=\mathrm{Ce}^{3+}+\mathrm{SO}_{4}^{2-}$ 控制. 若 反应过程中维持 $\mathrm{As}(\mathrm{III}), \mathrm{Ce}^{3+}$ 和 $\mathrm{SO}_{4}^{2-}$ 恒定, 则得到

$$
\begin{gathered}
E=E^{0}+\frac{R T}{F} \ln [\mathrm{Ce}(\mathrm{IV})], \\
-V=-\frac{d E}{d t}=K_{0}+K_{\mathrm{l}}[\mathrm{I}]+K_{s} S,
\end{gathered}
$$

式中 $V$ 是电位变化速度, $K_{0}, K_{\mathrm{I}}$ 和 $K_{s}$ 分别等于 $\frac{R T}{F} k_{0}, \frac{R T}{F} k_{\mathrm{I}}$ 和 $\frac{R T}{F} k_{s}$. 又因 $K_{\mathrm{I}}$ 值亦受 盐度的影响, 故 (4) 式可表示为

$$
-V=-\frac{d E}{d t}=K_{0}+\left(K_{1}^{0}+K_{1}^{\mathrm{s}} S\right)[\mathrm{I}]+K_{s} S \text {. }
$$

本文 1980 年 1 月 31 日收到。 
通过实验求得各常数后, 可由海水盐度及 $V$ 值计算碘浓度. 为了消除 $K_{\mathrm{I}}$ 值变动所造成的分析

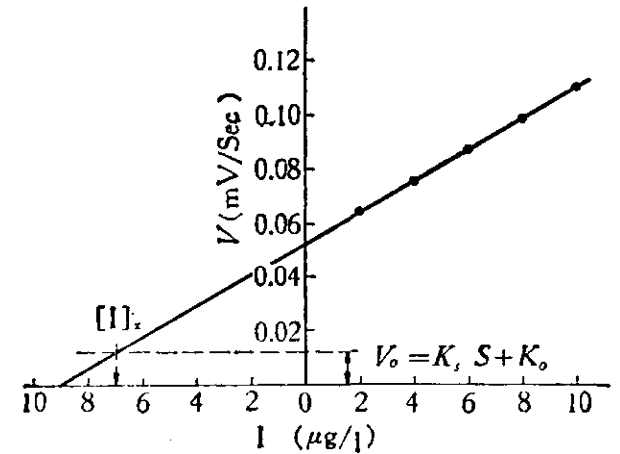

图 1 多次标准添加作图法示例 注: 图中纵座标均为负值, $V_{0}$ 为 $-V_{0}$ 误差,宜采用标准添加法, 此时

$$
[\mathrm{I}]_{x}=[\mathrm{I}]_{n} \frac{V_{x}+K_{S} S+K_{0}}{V_{n}},
$$

$[\mathrm{I}]_{x}$ 是未知液浓度, $[\mathrm{I}]_{n}$ 是第 $n$ 次标准添加后磑 浓 度的总增量, $V_{x}$ 和 $V_{n}$ 分别为未知液的电位变化速 度和第 $n$ 次标准添加后的总增量. 通过多次标准添加 作图法 (见图 1) 所得结果将更为准确可靠.

间隙水与海水大体相似, 情况亦如前述. 人工降雨 中杂质较少,当固定盐度后,(4)、(6)两式简化如下:

$$
\begin{aligned}
& -V=K_{\mathrm{I}}[\mathrm{I}]-V_{\mathrm{c}}, \\
& {[\mathrm{I}]=[\mathrm{I}]_{n} \frac{V_{x}-V_{0}}{V_{n}},}
\end{aligned}
$$

$-V_{0}=K_{s} S+K_{0}$, 系本底值.

\section{实 验 部 分}

$0.015 M$ 硫酸铈铵溶液、 $0.20 M$ 亚砷酸钠溶液、硔标准溶液、2.00M 氯化钠溶液、 $0.100 M$ 澳化钠溶液和无碘人工海水,均用分析纯试剂配制.

电位指示电极是玻璃石墨电极和铂电极, 参比电极是双盐桥饱和甘录电极. 电位测量采 用高阻抗 $\left(10^{12} \Omega\right)$ 电位差计, 全量程为 $20 \sim 400$ 毫伏 $/ 250$ 毫米, 并由 $\mathrm{KWT}-100$ 型记录仪笔 录电位变化 ${ }^{[7]}$. 光度测定采用 721 分光光度计.

实验温度 $30 \pm 0.1^{\circ} \mathrm{C}$, 磁力搅拌速度 $600 \pm 20$ 转/分.

海水取自胶州湾,间隙水取自渤海湾*。盐度用莫尔法测定.

实验表明:

玻璃石墨电极的电位响应性能优于铂电极. 当溶液中含有 $[\mathrm{Ce}(\mathrm{IV})]=[\mathrm{Ce}(\mathrm{III})]=$ $0.010 \mathrm{M},\left[\mathrm{SO}_{4}^{2-}\right]=1.0 \mathrm{M}$ 时玻璃石墨电极的电位迅速稳定在 1.195 伏, 与文献值 ${ }^{[8]}$ 相一致, 并 且 $\frac{\partial E}{\partial \log [\mathrm{Ce}(\mathrm{IV})]}=0.062$ 伏. 当 $\mathrm{Ce}(\mathrm{IV})-\mathrm{As}$ (III) 之间发生反应时电位部分受动力学因素 影响而略低于平衡值, 但在 1.05-0.90 伏区间内电位呈直线变化, 在碘浓度为 $0.2-100$ 微克/ 升范围内,其变化速度与碤浓度呈线性关系(图 2).

在 $15^{\circ}-35^{\circ} \mathrm{C}$ 所测催化反应活化能为 42 千焦耳/摩尔.

根据实验数据导出以下经验公式:

$$
\left.\begin{array}{l}
-\left(\frac{d E}{d t}\right)_{30^{\circ} \mathrm{C}}=(0.0055+0.000014 S) \frac{\mathrm{mV} \cdot 1}{\mathrm{sec} \cdot \mu g}[\mathrm{I}]+0.00025 S \frac{\mathrm{mV}}{\mathrm{sec}}+0.0033 \frac{\mathrm{mV}}{\mathrm{sec}} \\
-\left(\frac{d E}{d t}\right)_{20^{\circ} \mathrm{C}}=(0.0029+0.000007 S) \frac{\mathrm{mV} \cdot 1}{\mathrm{sec} \cdot \mu g}[\mathrm{I}]+0.000069 S \frac{\mathrm{mV}}{\mathrm{sec}}+0.0010 \frac{\mathrm{mV}}{\mathrm{sec}}
\end{array}\right\}
$$

\footnotetext{
*间隙水由中国科学院海洋研究所朱晓斌等同志采样和压滤.
} 
显然, $\left(\frac{\partial K_{S}}{\partial T}\right)_{s} \approx\left(\frac{\partial K_{0}}{\partial T}\right)_{s}>\left(\frac{\partial K_{\mathrm{I}}}{\partial T}\right)_{s}$, 故温度较低时本底的相对值较小, 干扰亦小. (7)式 中 [I] 的单位是微克/升, 实验得出 $\left(K_{1} / K_{\mathrm{cl}}\right)_{30^{\circ} \mathrm{C}}=1.4 \times 10^{6},\left(K_{\mathrm{I}} / K_{\mathrm{cl}}\right)_{20^{\circ} \mathrm{C}}=2.7 \times 10^{6}$, 海水 中的主要干扰物种是氯离子, 而不是溴离子, 此与 Truesdale ${ }^{[5]}$ 结果一致.

人工降雨中的银干扰测定, 加人一定量 $(0.01-0.05 M)$ 的氯化钠可掩蔽之, 并能起 到维持盐度恒定和提高催化反应速度的作 用 $^{[3]}$.

电位法与光度法所得结果一致, 但前者 灵敏度高, 参数变化的线性范围较宽, 并适于 微样测定和自动记录.

采用多次标准添加作图法, 分析的相对 标准误差是 3\%, 实验回收率是 $97 \sim 103 \%$. 固定电位变化法操作简便、版定温、适于现 场分析, 配合标准添加法定量, 其相对误差约 为 $5 \%$ 。

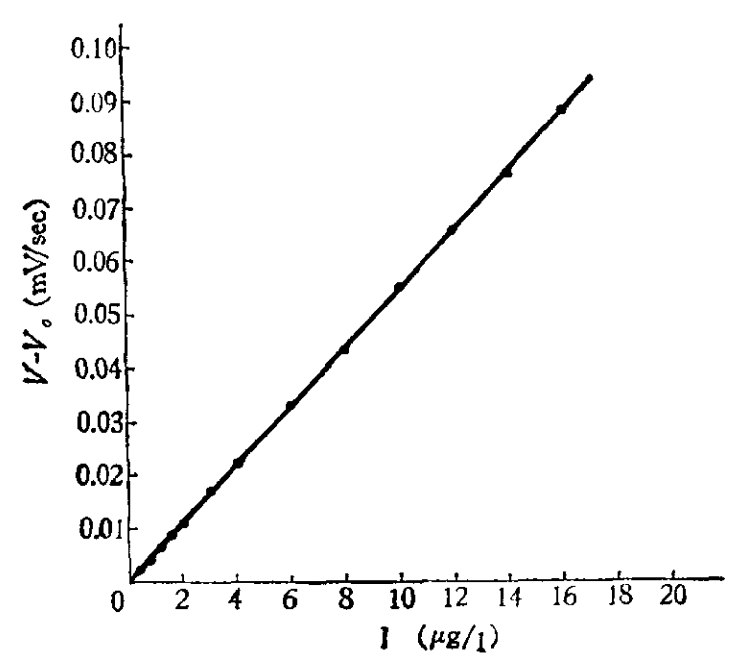

图 2 电位变化速度与碘浓度的关系 注: 图中纵座标均为负值

一般样品分析步骤如下:

海水样品移取 5.0 毫升海水, 5.0 毫升 $0.20 M$ 亚砷酸钠、35.0 毫升二次水置于 50 毫 升烧杯中, 恒温 $30^{\circ} \mathrm{C}$ (或 $20^{\circ} \mathrm{C}$ ). 加入 5.0 毫升相同温度的 $0.015 \mathrm{M}$ 的硫酸铈铵, 并立即将预 表 1 样品分析结果

\begin{tabular}{|c|c|c|c|c|c|c|c|c|c|c|c|}
\hline \multirow{2}{*}{ 样 } & \multirow{2}{*}{ No. } & & \multirow{2}{*}{ 度 $(S \% 0)$} & & \multirow{2}{*}{$\hat{(\mu \mathrm{g} / 1)}^{\text {碘 }}$} & \multicolumn{2}{|r|}{ 测 } & \multirow{2}{*}{$\begin{array}{l}\text { 定 } \\
\text { 法 }\end{array}$} & \multicolumn{3}{|c|}{$(\mu \mathrm{g} / 1)$} \\
\hline & & & & & & 电 & 位 & & 光 & 度 & 法 \\
\hline 海水 & 1 & & 30.56 & & 0 & & 44 & & & 42 & \\
\hline 海水 & 1 & & & & 50 & & 96 & & & 97 & \\
\hline 海水 & 2 & & 31.70 & & 0 & & 48 & & & 45 & \\
\hline 海水 & 2 & & & & 50 & & 101 & & & 100 & \\
\hline 海水 & 3 & & 32.76 & & 0 & & 52 & & & 54 & \\
\hline 海水 & 3 & & & & 50 & & 100 & & & 106 & \\
\hline 人工海水 & 1 & & 35.13 & & 50 & & 51 & & & 48 & \\
\hline 人工海水 & 1 & & 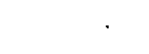 & & 100 & & 102 & & & 104 & \\
\hline 人工海水 & 2 & & 29.28 & & 50 & & 52 & & & 46 & \\
\hline 人工海水 & 2 & & & & 100 & & 103 & & & 103 & \\
\hline 间隙水 & 4 & & 30.41 & & 0 & & 237 & & & - & \\
\hline 间纱水 & 4 & & & & 100 & & 329 & & & - & \\
\hline 间隙水 & 13 & & 30.12 & & 0 & & 67 & & & - & \\
\hline 间隙水 & 13 & & & & 50 & & 122 & & & - & \\
\hline 人工降雨 & 1 & & 0.01 & & 0 & & 1.6 & & & 1.4 & \\
\hline 人工降雨 & 1 & & & & 2.9 & & 3.7 & & & 3.6 & \\
\hline 人工降雨 & 3 & & 0.04 & & 0 & & 4.4 & & & 4.5 & \\
\hline 人工降雨 & 3 & & & & 2.0 & & 6.2 & & & 6.2 & \\
\hline 人工降雨 & 4 & & 0.05 & & 0 & & 2.3 & & & 2.4 & \\
\hline 人工降雨 & 4 & & & & 2.0 & & 4.2 & & & 4.2 & \\
\hline
\end{tabular}


先浸泡在 $0.0015 \mathrm{M}$ 硫酸铈铵溶液中的玻璃石墨电极插人, 待电位降至 1.05 伏时开始记录电位 变化曲线,其间添加已知量标准碘溶液,由记录下来的各线段斜率值进行定量. 若采用固定电 位变化法,由一次标准添加定量时, 可在常温下操作.

间隙水样品因样品量少而取 1.0 毫升，余者均照比例减少，测定体系定容 10.0 毫升. 操作步聚同海水.

人工降雨样品 取样 25.0 毫升, 加人 1.0 毫升 $2 M$ 氯化钠和 14.0 毫升二次水, 余者同 海水.

样品分析结果部分列于表 $1 、$ 表 2.

表 2 固定电位变化法分析结果*

\begin{tabular}{|c|c|c|c|c|c|c|c|c|}
\hline \multirow{2}{*}{ 样＼cjkstart品 } & \multirow{2}{*}{ No. } & \multicolumn{3}{|c|}{ 测 } & 结 & \multicolumn{2}{|r|}{$(\mu \mathrm{g} / \mathrm{L})$} & \multirow[b]{2}{*}{ 标准误淸 } \\
\hline & & 第一次 & 第二 次 & 第三 次 & 第 四次 & 第五次 & 平均值 & \\
\hline 游水 & 1 & 43 & 45 & 40 & 41 & 43 & 42.4 & 2.0 \\
\hline 海水 & 3 & 50 & 48 & 46 & 53 & 51 & 49.6 & 2.7 \\
\hline 人工海水 & 1 & 54 & 54 & 51 & 52 & 48 & 51.8 & 2.5 \\
\hline 人工淑水 & 2 & 53 & 55 & 50 & 54 & 49 & 52.2 & 2.6 \\
\hline 间隙水 & 4 & 221 & 233 & 230 & 249 & 254 & 237 & 14 \\
\hline 间隙水 & 13 & 61 & 58 & 70 & 73 & 69 & 66.2 & 6.4 \\
\hline 人工降雨 & 1 & 1.3 & 1.5 & 1.6 & 1.3 & 1.5 & 1.44 & 0.13 \\
\hline 人工降雨 & 8 & 3.3 & 3.2 & 3.4 & 3.2 & 3.5 & 3.32 & 0.13 \\
\hline
\end{tabular}

*室温下进行,由一次标准添加定量.

\section{参考文献}

[1] Barkley, R. A. \& Thompson, T. G., Anal. Chem., 32(1960), 154.

[2] Sandell, E. B. \& Kolthoff, I. M., Am. Chem. Soc., 56(1934), 1426.

[3] Dubraveic, M., Analyst, 80(1955), 295.

[4] Hadjioannou, T. P., Anal, Chim. Acta, 30(1964), 488.

[5] Truesdale, V. W. \& Sponcer, C. P., Marine Chem., 2(1974), 33.

[6] Truesdale, V. W. \& Chapman, P., Marine Chem., 4(1976), 29.

[7] 山东海洋学院, 海洋用钢腐蚀研究 (上海钢铁研究所主编), 上海科学技术出版社, 1978, 167.

[8] Latimer, W. M., The Oxidation States of the Elements and Their Potentinls in Aqueous Solutions, 2nd ed., Prentice-Hall ine., New York, 1952, 294. 